\title{
An Economic Investigation of Confiscation as a Tool against Money Laundering
}

Ricardo Azevedo Araujo

Department of Economics, Universidade de Brasília (UnB), Brazil

Tito Belchior Silva Moreira

Department of Economics, Universidade Católica de Brasília (UCB), Brazil

\begin{abstract}
In this paper the efficiency of the confiscation as a tool against organized crime is studied by using a general equilibrium model that considers the existence of a representative criminal organization that generates profits that need to be laundered. The main result of the paper shows that if on one hand confiscation diminishes the optimal amount of money laundered on the other it increases the fraction of resources allocated to the criminal activity. This result suggests that confiscation has to be connected to further repressive measures in other to be an efficient tool against organized crime.
\end{abstract}

Keywords: Money Laundering, Organized Crime, Confiscation

JEL Classification: K-14, K-42

\section{Resumo}

Neste artigo, a eficiência do confisco como uma ferramenta contra o crime organizado é estudado usando um modelo de equilíbrio geral que considera a existência de uma organização criminosa representativa que gera lucros que precisam ser lavados. O principal resultado do trabalho mostra que se por um lado a perda associada ao confisco diminui a quantidade ideal de dinheiro lavado, por outro lado, aumenta a fração dos recursos alocados à atividade criminal. Este resultado sugere que o confisco tem que ser ligado a medidas repressivas em outro a ser um instrumento eficaz contra o crime organizado.

\footnotetext{
ऋ Submitted in August 2010, Accepted in April 2012.

E-mail addresses: rsaaraujo@unb.br, tito@pos.ucb.br
} 


\section{Introduction}

The study of the combat against organized crime has won new and revealing insights with the understanding that the struggle against the activity that allow it to refinance, that is money laundering, plays a central role in this combat. Money laundering allows concealing the origins of illegal profits and provides resources to reinvestment in the illegal activity. In this vein confiscation may be an important tool against the organized crime since it is considered one of the main tools if not the main one against money laundering.

Since money laundered is what allows transforming potential purchasing power into an effective one a number of countries has approved laws that allow the confiscation of resources. One of the characteristics of some activities that generate illegal profits that need to be laundered is that it is not easy to identify or in some cases it is impossible to do it the person who suffered the damage due to the activity. Then it is difficult to prosecute the offenders based on a legal system that do not allow the confiscation of the proceeds from criminal activity. In this vein the use of confiscation as a tool against money laundering is a great advance to combat organized crime.

However, in the literature there is no consensus on the results produced by confiscation. Lusty (2002) for instance has reported that "conviction-based confiscation laws in Australia, like their counterparts in the UK, have proven grossly inadequate to deprive contemporary criminals of their ill gotten gains." According to this author the civil forfeiture laws are more effective than the conviction based confiscations in a number of countries.

This view is disputed by Stessens (2000, p. 30). According to this author "The confiscation of proceeds from crime is of relatively recent vintage and aims to enhance the effectiveness of criminal justice in its fight against any type of profit driven crime." This author believes that the policy of not allowing the criminals to enjoy the ill gotten gains of criminal activities is the main barrier against the proliferation of money laundering.

While the efficiency of confiscation has been focused from a law perspective little attention has been given to its economic efficiency as a tool against money laundering. The main goal of criminal organizations is to generate profits and from this perspective it is possible to evaluate the effects of confiscation on the allocation of illegal resources. A related study to this matter is the work by Chiu et al. (1998) that departs from the assumption that confiscation is the only mechanism against drug production and traffic. Their result became known in the literature as the irrelevance battlefield proposition and states that it does not matter if the confiscation is carried on against drug traffic or production.

Such a result may be disputed in the light of the workings of a number of authors who show that not only the combat against drug production and traffic but also the optimal allocation of resources devoted to this combat plays a central role in this fight [See Araujo and Moreira (2004), Tragler et al. (2001) and Behrens 
et al. (1999)]. Although these authors do not mention confiscation explicitly their analysis entails law enforcement in its broad sense.

In fact the gap in the literature of economic analyzes of confiscation as a tool against criminal activities reflect the fact that there are few papers that formalize the connection between criminal activities and money laundering. Masciandaro (1999) is an exception. He considers money laundering as a multiplier of criminal financial activities. According to him such "polluting" element of the economy becomes more considerable the larger the share of reinvestment in illegal activities.

Araujo (2006) models the connection between money laundering and terrorism and shows that an efficient combat against terrorism is made through a combination of repressive measures against the criminal activities that finance it and against the procedures to money launder the profits from crime. Although these papers tackle the issue of money laundering and organized crime none of them made an economic analysis of the efficiency of confiscation as a measure against money laundering.

The present paper intends to fill this gap. By using a general equilibrium model with an illegal representative organization it shows that on one hand confiscation diminishes the optimal amount of money laundered but on the other hand it increases the fraction of resources allocated to the criminal activity. In this vein it may not be an efficient tool against money laundering if it is not carried out along with some other repressive measures against the criminal activity that generates the illegal profits since an increase in confiscation index without auxiliary measures of repression may induce the offender to reinvest higher proportions of his profits in the illegal activity to compensate the effects of confiscation.

This paper is structured as follows: in the next section the derivation of the basic model is presented. The first version of the model departs from a discrete version of the Masciandaro's model (1999) to obtain a differential equation that conveys the dynamic evolution of investment in a criminal organization. Once this equation is established the optimal value of the fraction allocated in the illegal activity is established. In Section 3, the basic model is extended to consider that the criminal organization chooses not only the fraction of receipt that will be laundered but also the fraction of workers that will be allocated to perform the criminal activity and launder the dirty money. In both sections the effects of the confiscation on the amount of money laundered and on the fraction of resources allocated to the criminal activity is analyzed by using a static comparative approach. In Section 4, a numerical simulation based on the extended model of Section 3 is performed to illustrate the working of the model. Section 5 concludes.

\section{The Model}

The model departs from Masciandaro (1999) by assuming that $R(t)$ is the receipt of criminal activity in period $t$. It is assumed that the rate of return of the criminal activity is given by $r$. In this vein the receipt in period $t$ is given by: 


$$
R(t)=(1+r) I(t)
$$

where $I(t)$ is the investment made in period $t$. The amount of money laundered in period $t$ is a function of the receipt generated by the criminal organization, that is $M(t)=(1-\varepsilon) R(t)$ where $\varepsilon, 0<\varepsilon<1$, is the amount of the receipt that is lost due to confiscation. The agents that practices illegal activities has motivation to laundering the total amount of the receipt that is not lost due to confiscation, because it allows concealing the origins of illegal profits and provides resources to reinvestment in the illegal activity. By substituting expression (1) into the expression of money laundering yields:

$$
M(t)=(1-\varepsilon)(1+r) I(t)
$$

Let us assume that in the next period, that is $t+1$, a fraction $q, 0<q<1$, is reinvested in the illegal activity. In this vein the investment in period $t+1$ is given by:

$$
I(t+1)=q M(t)=q(1-\varepsilon)(1+r) I(t)
$$

By subtracting both sides of (3) by $I(t)$ and after some algebraic manipulation it is possible to obtain the discrete growth rate of the investment in the illegal activity as:

$$
\frac{\triangle I}{I}=[q(1-\varepsilon)(1+r)-1]
$$

where $\triangle I$ stands for the difference between $I(t+1)$ and $I(t)$. Taking the limit of expression (4) when $\Delta t \rightarrow 0$ allows us to obtain the continuous counterpart this expression, that is:

$$
\frac{\dot{I}}{I}=[q(1-\varepsilon)(1+r)-1]
$$

which gives the continuous growth rate of the investment of the criminal organization. The change in investment is then given by the following expression:

$$
\dot{I}=[q(1-\varepsilon)(1+r)-1] I
$$

Hence the problem of the representative criminal organization is to maximize his intertemporal discounted profit. Since the actual profit of firm in each period is given by $(1+r) I-q M$ the problem of the criminal organization may be expressed as:

$$
\max \int_{0}^{\infty}[(1+r) I-q M] e^{\theta t} d t
$$

subject to (5)'. In order to solve this problem let us introduce the Hamiltonian function:

$$
H=(1+r) I-q M+\mu I[q(1+r)(1-\varepsilon)-1]
$$


where $\mu$ is the co-state variable associated to the state variable $I$. The control variable of this problem is $q$, that is, the fraction of investment that is allocated to the illegal activity. The first order condition is then given by:

$$
H_{q}=0 \Rightarrow M=I(1+r)(1-\varepsilon)
$$

The Euler condition is given by:

$$
\dot{\mu}-\theta \mu-=\frac{\partial H}{\partial I}=-\mu[q(1+r)(1-\varepsilon)-1]-(1+r)
$$

This model presents closed form solutions. From expression (5) evaluated in steady state it is possible to obtain the optimal values of $q^{*}$ :

$$
q^{*}=\frac{1}{(1+r)(1-\varepsilon)}
$$

In order to meet the requirement on the value of $q$, that is $0<q^{*}<1$ this result requires that: $\varepsilon>1-(1 / 1+r)$, which is a reasonable assumption since $0<\varepsilon<1$. From expression (9) evaluated in steady state it is possible to obtain the value of $\mu^{*}$ :

$$
\mu^{*}=\frac{1+r}{\theta}
$$

The optimal amount of money laundered as a function of the investment made is given by expression (8):

$$
M^{*}=I(1+r)(1-\varepsilon)
$$

The optimal values of $q^{*}$ and $M^{*}$ play a central role in this analysis. Note that:

and

$$
\frac{d q^{*}}{d \varepsilon}=\frac{1+r}{(1+r)(1-\varepsilon)}>0
$$

$$
\frac{d M^{*}}{d \varepsilon}=-I(1+r)<0
$$

Expressions (13) and (14) show two opposite effects of the confiscation on money laundering. The former shows that the higher the confiscation indexes the higher the investment in the illegal activity. This result may be surprising at a first glance but it shows that the higher the losses due to confiscation the higher the fraction of investment that the criminal organization has to do in order to compensate the losses and maximize profit. This result shows that confiscation without enforcement against the activity that yields the profits to be laundered may be a misleading policy. Expression (14) shows that the higher the confiscation the smaller the amount laundered. In fact, this result is explained by equation 2 , which is a hypothesis of the model. In the next section these results are shown to be robust to an extension of the model that considers not only the allocation of investment as a control variable but also the allocation of the labor force employed by the criminal organization. 


\section{An Extended Model}

Let us consider an extended version of the previous model that contemplates the possibility of the criminal agent to engage into two activities: one is the illegal activity that yields profits that needed to be laundered which in general has a legal appearance which aims to embezzle the illegal profits generated in the former activity. Let us assume that $\alpha$ is the fraction of labor force, or man hours, employed in the illegal activity, $0<\alpha<1$. Being $L$ the total amount of labor $\alpha L$ stands for the amount of the labor force employed in the illegal activity and $(1-\alpha) L$ is the amount of the labor force employed in the money laundering activity. Let it $R(t)$ be the receipt of the illegal activity. In order to generate closed form solutions that allow a numerical simulation this receipt is assumed to be a linear function of a fraction $q, 0<q<1$, of investment $I(t)$ and of man hours spent in the illegal activity:

$$
R(t)=q I(t) \alpha L(t)
$$

The receipt of the illegal activity can also be written as: $R(t)=(1+r) q I(t)$ as in the previous section. But now the rate of return is an endogenous variable, which is equal to: $r=\alpha L-1$. Let us also assume that a fraction $0<\varepsilon<1$ of the receipt is lost due to confiscation. From the remaining, that is $(1-\varepsilon) R(t)$, a fraction $0 \leq l \leq 1$ is laundered. Let us assume that $l$ is an increasing function of the number of men-hours that is allocated to perform the money laundering activity, that is $l=f[(1-\alpha) L]$. For the sake of simplicity only let us assume that $l=f[(1-\alpha) L]=(1-\alpha) L$. The amount of money laundered $M(t)$ is a function not only of the receipts but also of the fraction of this receipt that is laundered and the amount of money that is left after confiscation:

$$
M(t)=(1-\varepsilon) l R(t)
$$

The criminal organization faces a trade-off here. On one hand if it chooses a higher fraction of the labor force to perform the criminal activity it has a higher receipt but a smaller fraction of the receipt will be laundered which means a higher risk of having the illegal source of its resources discovered. By following the rationale of the previous section let us assume that the investment in period $t+1$ is given by:

$$
I(t+1)=q M(t)=q(1-\varepsilon) l R(t)
$$

By substituting (15) into (16)

$$
I(t+1)=q M(t)=q^{2}(1-\varepsilon) l I(t) \alpha L(t)
$$

By subtracting both sides of (17) by $I(t)$

$$
I(t+1)-I(t)=I(t)\left[q^{2}(1-\varepsilon) l \alpha L(t)-1\right]
$$


we obtain

$$
\dot{I}(t)=I(t)\left[q^{2}(1-\varepsilon) l \alpha L(t)-1\right]
$$

The problem to be solved is:

$$
\max \int_{0}^{\infty}[(1+r) I-q M] e^{\theta t} d t
$$

subject to (20). Noticing that the equation 21 is equal to equation 6 . By substituting $l=(1-\alpha) L$ into expression (20) and considering that $\mu$ is the co-state variable associated to the state variable $I$ let us form the following Halmitonian:

$$
H=(1+r) I-q M+\mu I\left[q^{2}(1-\varepsilon)(1-\alpha) \alpha L^{2}-1\right]
$$

The first orders conditions are:

$$
\begin{aligned}
& H_{q}=0 \Rightarrow M=\mu l(1-\varepsilon) 2 q l \alpha L \\
& H_{\alpha}=0 \Rightarrow \mu I(1-\varepsilon) q^{2} L^{2}(1-2 \alpha)=0
\end{aligned}
$$

The Euler condition yields:

$$
\dot{\mu}-\theta \mu=-\frac{\partial H}{\partial I}=-\mu\left[q^{2}(1+r)(1-\varepsilon)\left(\alpha-\alpha^{2}\right) L^{2}-1\right]-(1+r)
$$

From expression $(24)$ and since $\mu I(1-\varepsilon) q^{2} L^{2} \neq 0$ we conclude that:

$$
\alpha^{*}=\frac{1}{2}
$$

This solution shows that it is optimal to the criminal organization to allocate half of the labor force in the criminal activity that yields the profits to be laundered and half of the labor force to the activity of money laundering. From expression (20) evaluated in steady state and (26) we conclude that:

$$
q^{*}=\sqrt{\frac{2}{(1-\varepsilon) L^{2}}}
$$

Since $0<q^{*}<1$ the above result requires that $L>(2 / 1-\varepsilon)^{\frac{1}{2}}$. Expression $(27)$ shows that the optimal value of the fraction of the investment in the illegal activity depends on the index of confiscation and on the amount of labor force employed in the joint process of criminal activity and money laundering. Expression (25) evaluated in steady state yields the optimal value of the co-state variable in steady state:

$$
\mu=\frac{(1+r)}{\left[\theta-q^{2}(1+r)(1-\varepsilon)\left(\alpha-\alpha^{2}\right) L^{2}+1\right]}
$$

In this extended version of the model the value of the rate of return $r$ is endogenously determined by $r=\alpha L-1$, which yields by substituting expression $(26)$ : 


$$
r^{*}=\frac{1}{2} L-1
$$

Araujo and Moreira (2004) analyze the proliferation of drugs by using a dynamic model. The model shows that equilibrium with no dealers and producers is fairly difficult. The relation between costs and benefits is not favorable to obtain a null rate of criminal activities. The costs for the taxpayer would be prohibited. In this sense, the illegal activities can be kept at low levels if the repression against these activities is great enough, but some level of criminality always will occur. Hence, the rate of return $\mathrm{r}$ must be positive, i.e., $\alpha>1 / L$. Based in stylized facts, we can argue that how the money laundering activities is associated with the organized crime and these activities generate higher operational costs, then it is necessary that organized crime operate with economy of scale. Consequently, it is reasonable argue that the rate of return $r$ is positively correlated with the term $\alpha L$, which is a proxy for the market size.

By substituting the optimal values of $\alpha^{*}, q^{*}$ and $r^{*}$ in the expression (28) allows us to obtain the optimal value of the co-state variable, that is:

$$
\mu^{*}=\frac{2 L}{4 \theta+2-r}
$$

By substituting the values of $\alpha^{*}, q^{*}, r^{*}$ and $\mu^{*}$ into expression (23) it is possible to obtain the value of $M^{*}$ as a function of the investment made, that is:

$$
M^{*}=\frac{I[(1-\varepsilon) 2]^{1 / 2} L^{2}}{4 \theta+1+(L / 2)}
$$

By taking the derivative of $q^{*}$ with respect to $\varepsilon$ we conclude that:

$$
\frac{d q^{*}}{d \varepsilon}=\frac{1}{2} \sqrt{\frac{2}{(1-\varepsilon) L^{2}}>0}
$$

By taking the derivative of $M^{*}$ with respect to $\varepsilon$ yields:

$$
\frac{d M^{*}}{d \varepsilon}=-\frac{L^{2} I[2(1-\varepsilon)]^{-1 / 2}}{8 \theta+2+L}<0
$$

These results are analogous to the previous section, that is, one on hand the higher the confiscation indexes the higher the investment in the illegal activity and on the other hand the higher the confiscation the smaller the amount laundered. The flavor of this result is that the criminal organization intends to compensate a higher confiscation index by allocating a higher fraction of investment to yields illegal profits which may stimulate the illegal activity. In this vein the amount of money laundered diminishes but the criminal activity may increase. 


\section{Conclusion}

In this paper the efficiency of the confiscation as one of the main tools against money laundering was studied by using a general equilibrium model that considers the existence of a representative criminal agent engaged in an illegal activity that generates profits that need to be laundered. Confiscation is one of the main tools against money laundering. However it is shown in this paper that it may not be an efficient tool against money laundering if it is not carried out along with some other repressive measure against the criminal activity that generates the profit. Along the same line, Moreira (2007) argues that the law enforcement organizations must improve their services of repression, prevention, investigation and dissuasion of organized crime and money laundering activities. Moreira (2007) also shows that the effectiveness of anti-money laundering policies and a higher probability of punishment for the criminal acts reduce the incentive to illegal activities.

This result arises due to the fact that if only confiscation is adopted the higher the confiscation the higher the fraction of the investment that the criminal agent decides to reinvest in the illegal activity in order to compensate the loss due to confiscation. Stessens (2000, p. 50) acknowledges that "[t]he confiscation of the proceeds from drug trafficking will often have no relation at all to the social and economic damage that has been caused by the drug trafficking." Although confiscation may be an efficient tool against money laundering it cannot be an efficient measure to combat the criminal activity that generates the profit if it is not combined with law enforcement. 


\section{References}

Araujo, R. (2006). The effects of money laundering and terrorism on capital accumulation. Journal of Money Laundering Control, 9:265-271.

Araujo, R. \& Moreira, T. (2004). A dynamic model of production and traffic of drugs. Economics Letters, 82:371-376.

Behrens, D., Caulkins, J., Tragler, G., Haunschmied, J., \& Feichtinger, G. (1999). A dynamic model of drug initiation: implications for treatment and drug control. Mathematical Biosciences, 159:1-20.

Chiu, S., Mansley, E., \& John, M. (1998). Choosing the right battlefield for the war on drugs: An irrelevance result. Economics Letters, 59:107-111.

Lusty, D. (2002). Civil forfeiture of proceeds of crimes in Australia. Journal of Money Laundering Control, 6:345-359.

Masciandaro, D. (1999). Money laundering: The economics of regulation. European Journal of Law and Economics, 7:225-240.

Moreira, T. B. S. (2007). A two-period model of money laundering and organized crime. Economics Bulletin, 11:1-5.

Stessens, G. (2000). Money Laundering: A New International Law Enforcement Model. Cambridge University Press.

Tragler, G., Caulkins, J., \& Feichtinger, G. (2001). Optimal dynamic allocation of treatment and enforcement in illicit drug control. Operations Research, 49:352-362. 